\title{
The Impact of Attachment Styles on Social Competence of Adolescent Students
}

\author{
D M Sujan Kumar* and S John Michael Raj ${ }^{\dagger}$
}

\begin{abstract}
Attachment styles are indispensable elements in evoking human behavior. Precious and priceless social relations or social behavior of every individual is ever more determined by these styles only. Adapting to positive well-being at home, school and peer adjustments are the essential social capabilities expected from the adolescents in order to have effective behavior potentials. Mostly, accomplishments and achievements of academic pursuits of adolescents seem to get initiated by the affectionate bond they receive either from their parents or from their caretakers. Hence, the current study seeks to sketch the probable link between attachment styles on the social competence of the adolescent students. Here, sample consists of 1152 male and 1188 female adolescent students. The Attachment Styles Questionnaire and The Adolescent Social Competence Scale were used to collect relevant data. Suitable statistical analyses were adopted for analyzing the data. The findings showed that the attachment styles seem to persuade the social competence of the adolescent students.
\end{abstract}

Keywords: Attachment styles, Social competence, Adolescent students

Research Scholar, Bharathiar University, Coimbatore, India; frsujankumar13@gmail.com

† Former Professor, Department of Psychology, Bharathiar University, Coimbatore, India; johnmichaelraj@rediffmail.com 


\section{Introduction}

The unearthing of the life span development of adolescents along with their attachment relationships has been considered imperative by recent researchers (Kobak \& Sceery, 1988; Shulman, Elicker, \& Sroufe, 1994; Rosenstein \& Horowitz, 1996). Attachment theory proposes that experiences with the primary caregivers are an important basis for the development of close social relationships outside the parent-child relationship. During the adolescent period, they gradually move from their family group to a peer group (Mabey \& Sorensen, 1995).Uniquely, having a greater amount of secure attachment style easily and effortlessly encourages them to emanate compassion and altruistic qualities facilitating them to have successful and satisfied adulthood (Mikulincer \& Shaver, 2005). Thus, the attachment styles promote far-reaching effects on the adolescents.

\section{Attachment styles and adolescence}

Attachment is a deep and enduring emotional bond that connects one person to another across time and space (Bowlby, 1969). This bond starts from childhood and endures lifelong. This naturally formed affective attribute energisesan individual to interact with outside world (Ainsworth, 1989).Further, initially a child finds its mother or caregiver as its primary attachment figure and as it grows the attachment expand to siblings, peers, friends, teachers and so on. And depending on the quality of the relationship experienced and expressed an array of attachment styles emerge. For instance, the individual receiving positive and caring support from their parents or caregivers grow naturally with secure attachment style otherwise they grow up with insecure attachment styles (Bowlby, 1988). Additionally, attachment theoreticians gradually evolved and explained attachment behaviours of individuals from these attachment styles. Initially, three styles of attachment, secure, ambivalent and avoidant styles have been advanced (Ainsworth, Blehar, Waters, \& Wall, 1978). Soon after, the styles have been conceived having positive and negative continuum and the negative continuum further bifurcated into preoccupied, dismissive and fearful attachment styles 
(Bartholomew \& Horowitz, 1991). Thus, individuals' grow with different styles of attachments.

Researchers have found that attachment patterns established early in life can lead to a number of outcomes. Children who are securely attached as infants tend to develop stronger self-esteem and better self-reliance as they grow and establish a set of attachment behaviours that provide for more satisfying relationships in the future (Thompson, 2000). Further studies have also reiterated the plausible persuading effect of positive secure attachments on the development and growth of cognitive abilities, executive functions, social communication skills, empathy, sociability, compliance with parents, self-control, behavioral regulation, emotional regulation, comfort, and very importantly, better peer relations with adolescents and successful social relationships (Kobak \& Sceery, 1988; Shulman, Elicker, \& Sroufe, 1994;Mikulincer \& Shaver, 2005). Similarly, positive growth and development during the adolescent period seem to emerge steadily and systematically through the impetus of positive and secure attachment styles (Allen, et al., 1998). That too gaining autonomy from parents and importance to peers easily takes place with those adolescents who have secure attachment styles (Armsden \& Greenberg, 1987). Again, exploring the new emotional terrain and forming of relationships with peers and romantic partners as well found to be effortless for the adolescents with secure attachment styles (Allen, et al., 1998). Therefore, it is evident that attachment styles do have a consistent and continuous connection with adolescent growth.

\section{Social Competence and Adolescents}

Effective human behaviour in general and adolescents behaviour, in particular, revolves around specific social capabilities. These capabilities are multifaceted in nature but aids in efficient social behaviour (McFall, 1982). Again, it certainly is a blending of complex skills, facilitating appropriate fitness in organizing social circumstances as well as promotes adequate interpersonal interactions of individuals (Osman, 2001). Yet again, it has been conceived as encompassing cognitive, emotional and behavioural components in prompting significant and successful human behaviour (Gresham \& Reschly, 1988). And these competencies are 
highly significant during the adolescent period in order to have enough social abilities and easily entering into adult social life (Elicker, Englund \& Sroufe, 1992).In fact, establish and sustaining in peer relationships is very much relays on the level of social competence of an adolescent. Higher competencies promise acceptance and admiration from peers, adaptive behavior, and social skills in the healthy social development of adolescents (Gresham \& Reschly, 1988).

Interacting normally with parents, peers and teachers enable the adolescents to have proper growth and development in their life. Especially, the quality of peer relationships found to be greatly contributed by the social competencies (Ladd, 1999). During the adolescent period, individuals establish mainly peer relationships which allowthem to learn more about oneself through sharing and support and to share confidence with close friends. The positive outcome of this developmental stage establishes a successful relationship with friends and peers. Actually, peer relations become a training ground for the future enhancement of interpersonal relationship and serve as a landmark in providing opportunities for upbringing reciprocity and intimacy among adolescents with society (Sanson \& Smart, 2003). Apart from these qualities, empathy, pro-social behaviors and concern for others also develop during this phase of life. And gaining membership in cliques to crowds is seen as an important feature of social life among adolescents (Brown \& Klute, 2003). Their strong conformity to peer pressures and expectations are due to their intense desire to belong or to be a part of a group (Ladd, 1999). Thus, social competence serves as a catalyst in emerging effectively during the adolescent period.

\section{Effect of Attachment on Social Competence of Adolescents}

The linkage between attachment styles and social competence is clear and candid. Reviews in this line have established the probable relationship between early attachments of adolescents and their present status of social competent behaviours. Indeed, the early childhood attachment experience has been viewed as the foundation for future social developments of the child (Ladd, 1999).The attachment experience of the adolescent is expected to 
influence their social competence in several ways and indicate that the quality of interactions and relationships between a child and parent and a child and peers are interconnected (Elicker, Englund \& Sroufe, 1992).In fact, even the very perception of the adolescents about their social competence have been influenced by their earlier evaluations of parents, teachers, peers and their own (Sanson \& Smart, 2003). Moreover, the positive family interaction between parents and adolescents encouraged the adolescents to experience their independence and individuation and energises them to develop required social competencies. Further, the good relationship of the adolescents with their family gradually allows them to form a secure attachment, self-worth of the adolescents and leads to better copings and adjustment their life (Ladd, 1999). The secure attachment with parents has been associated also with more positive effect, better relationships, and fewer behavioral problems with regard to peer relationships, when compared with insecure attachment with a parent; again, better adjusted to the intellectual, social, emotional, and behavioral demands of an early school environment than insecure children, who tend to be more rejected and less well-liked by peers (Granot \& Mayseless, 2001). Interestingly, the insecure attachment, avoidant and fearful attachment patterns in children are linked to higher levels of peer rejection, whereas preoccupied children tended to score in the average range on measures of peer rejection, but perceived this rejection rate to be much higher than that reported by their peers (Granot \& Mayseless, 2001).

\section{Methodology}

\section{Objective}

- To assess the effect of attachment styles on social competence of adolescent students.

\section{Hypothesis}

H.1. There will be asignificant difference between secure and insecure attachment styles on the social competence of adolescents. 
H.2. There will be significant effect of gender on social competence of adolescents

H.3. There will be asignificant interaction effect between the levels of attachment styles and gender on social competence of adolescents.

\section{Sample}

1152 adolescent male students and 1188 female students studying in class $\mathrm{X}$ and $\mathrm{XI}$ were systematically identified using purposive sampling technique from among the schools of Kanyakumari Educational District, Tamilnadu to constitute the sample for the present study.

\section{Procedure}

Official permission was obtained from the administrators of schools and the class teachersrendered their support to conduct the study in their respective classes. Participants were informed about the objectives and the outcome with regard to social implications of the study and their consent was taken before proceeding.The questionnaires were distributed to individual students and the data has been collected systematically.

\section{Research Instruments Used}

1. Attachment Style Questionnaire (ASQ; Van Oudenhoven, Hofstra and Bakker, 2003) Themodified version of the Attachment Style Questionnaire (ASQ) (Van Oudenhoven, Hofstra and Bakker, 2003) has 24 items. The internal consistencies (Cronbach's alpha) of the subscales by the original author of the ASQ are 0.75 for secure attachment style, 0.80 for preoccupied attachment style, 0.62 for the dismissive attachment style, and 0.79 for the fearful attachment style and its loading is also high $(>0.45)$ for the corresponding factors. The construct validity of the ASQ is also satisfactory. Hence, this tool was selected in the present study to measure the attachment style of the adolescents.

2. Adolescents Social Competence Scale (ASCS) (Viju P. Devassy and John Michael Raj 2012). The scale consists of 37 items with Likert scale model measuring eight factors 
such as school competence, teamorganizing competence, peer social competence, social cognition, home related social competence, social-emotional competence, social forethought and compassion, and social flexibility respectively. The scale has very high reliability and good face validity, content validity, item validity, intrinsic validity and factorial validity. The total split - half reliability scores of the scale is 0.87 which is good reliability measure.

\section{Data Analysis}

The data collected were systematically scored using the scoring procedures and the master sheet was prepared. The aim of the research is to find out the plausible relationships between the variables under study. Hence, the scores of the various attachment styles and their respective scores on social competence were subjected to a two-way Analysis of Variance. Thetwo-way ANOVA was carried out using SPSS package.

\section{Results and Discussion}

In order to test the hypotheses 1, 2 and 3 the data regardingsecure and insecure attachment styles and gender and theirinfluenceon the social competence of the adolescents, the scores were subjected to two-way ANOVA. The obtained results are presented in the following Table 1. 
Table 1: Summary of Two-Way ANOVA of the scores of Secure and Insecure Attachment Styles and Gender on Social Competence of the Adolescent students.

\begin{tabular}{|c|c|c|c|c|c|}
\hline Source & $\begin{array}{c}\text { Type III Sum of } \\
\text { Squares }\end{array}$ & $\mathrm{df}$ & $\begin{array}{l}\text { Mean } \\
\text { Square }\end{array}$ & $\mathrm{F}$ & Sig. \\
\hline $\begin{array}{l}\text { Between secure } \\
\text { and insecure } \\
\text { attachment } \\
\text { styles }\end{array}$ & 26535.170 & 1 & 26535.170 & 75.805 & .000 \\
\hline $\begin{array}{l}\text { Between } \\
\text { gender- boys } \\
\text { and girls }\end{array}$ & 27776.742 & 1 & 27776.742 & 79.352 & .000 \\
\hline $\begin{array}{l}\text { Interaction } \\
\text { between styles } \\
\text { and gender }\end{array}$ & 1509.851 & 1 & 1509.851 & 4.313 & .038 \\
\hline Error & 817703.269 & 2336 & 350.044 & & \\
\hline Total & 47549896.000 & 2340 & & & \\
\hline
\end{tabular}

${ }^{*} \mathrm{p}<.05$.

The calculated $f$ - ratio value relating to secure and insecure attachment styles on their social competence of adolescent students is75.80. It has attained statistical significance at .000 levels. Hence, hypothesis 1 is accepted. Similarly, the calculatedf-ratio relating to male and female is 79.35 and has attained statistical significance at .000 levels.Hence, hypothesis 2 is also accepted. The $f$-ratio value relating to interaction effect is 4.31 . It has also attained statistical significance at 0.05 levels. Therefore the third hypothesis is also accepted. The results are presented below in graphs $1,2 \& 3$. 


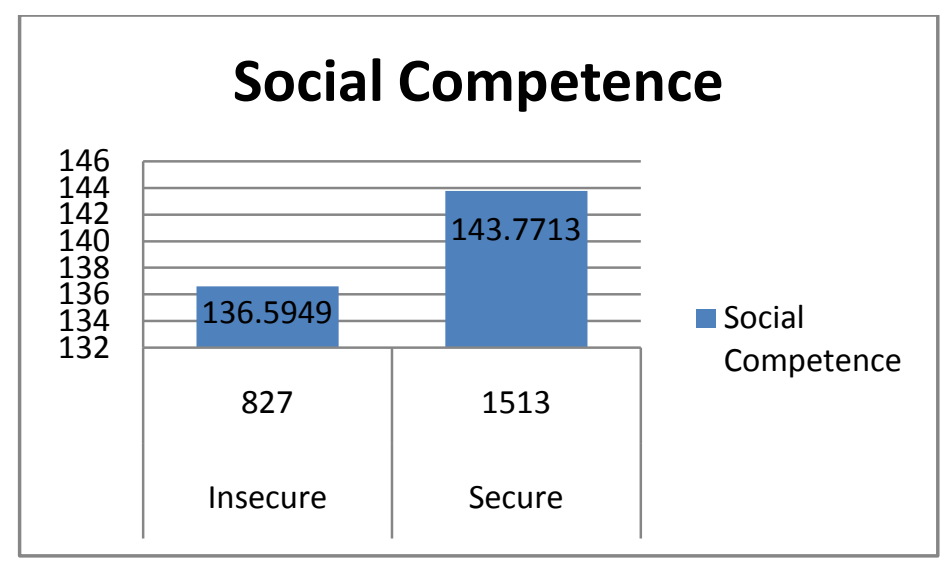

Fig1

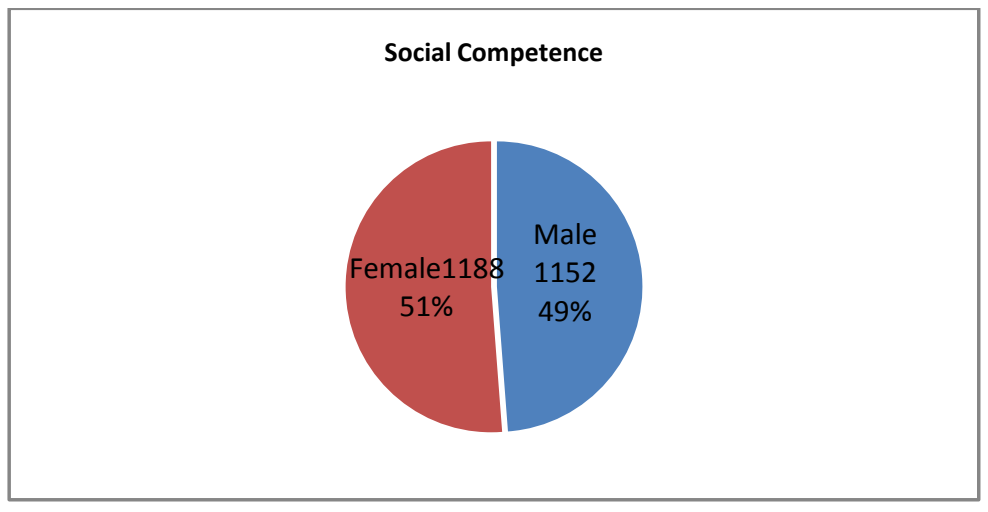

Fig2

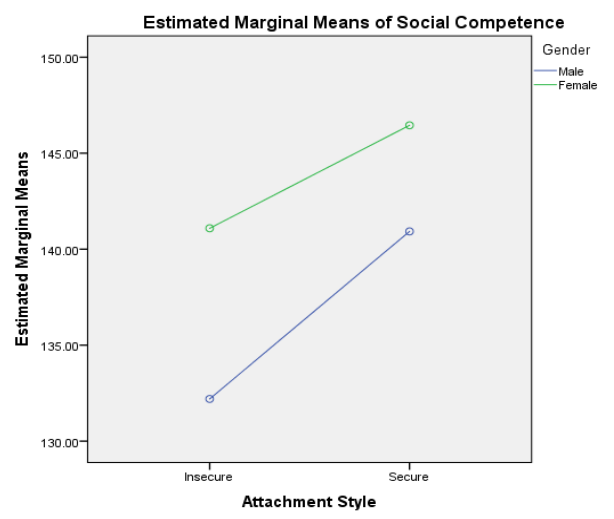

Fig3 


\section{Discussion}

The results of the study clearly brought out the feasible functions of attachment styles on the social competence of the adolescent students. The study revealedthe existence of systematic differenceon the levels of social competence between secure and insecure attachment style adolescent students. More specifically, the study has foundthat adolescent students with secure attachment styles are found to express higher levels of social competence. The existing empirical evidences exactly explain the view that experiencing secure attachment relationships with the parents as well as peers has enabled the adolescentstudents to grow and behave with greater sympathetic concern towards others, better prosocial behavior, and ever express extra positive affect with others whom they come into contact (Granot \& Mayseless, 2001). Similarly, safe and secure attachment between the infants and mothers promoted the infants to have lesser levels of aggressiveness, greater levels of friendship as well as cooperation with others along with significant association with social competence (Shulman, Elicker, \& Sroufe, 1994).In the same line, the attachment theorists have emphasised the attachment caregiving system has the inherent quality to initiate prosocial and sympathetic and if the attachment is safe and sound then the individual will show optimal functioning in his endeavours (Mikulincer \& Shaver, 2005). Furthermore, the early positive parent-child interactions could evoke positive social relations during the adolescent period as well (Granot \& Mayseless, 2001).It could be assumed that adolescents growing with secure attachment styles gain specific skills plus better preparedness to discover the art of graceful social relationships.

On the other hand, the results of the study could systematically and steadily discover that the adolescents with insecure attachment styles were unable to achieve enough social competence. The insecure attachment stylesin itself havea tendency to instigate troubles in relationships not only with oneself but also with others; and they find it difficult to go out to establish necessary relationships even with their fellow peers (Elicker, Englund \& Sroufe, 1992).Due to these reasons, the adolescents with insecure attachment are found to be unpopular among their peers and even 
they are rejected by their peers at times (Granot \& Mayseless, 2001). It seems that the internal working models of the self of the adolescents with insecure attachment styles neither could stimulate nor energise the person to receive proper attachment needs to be met by their caregivers (Bowlby, 1982).

The findings of the study also revealed there are a lot of variations between genders with regard to both experiencing and expressing the social competence by both the securely as well as insecurely attached adolescent students. The boys with secure attachment often found to mix with positive and socially competent play groups while the securely attached girls found to get along with negative and less socially competent playgroups (Denham, et al., 2001). And again, the adolescent girls having insecure attachmentstyle showed strongly passive tendencies, withdrawn in social situations, submissive in their approach, and are also neglected by their peers (Lefreniere \& Sroufe, 1985) ultimately revealing that the girls with insecure attachment have lesser social competence. Further, the insecure boys have very less social competence than the insecure girls (Cohn, 1990). In fact, both boys and girls differ significantly with regard attachment styles as well as social competence (Granot \& Mayseless, 2001). The present findings, as well as the existing reviews too, have clearly expressedthe observation that gender has a significant role both in gaining and using social competencies. The present finding on better social competencies for girls than for the boys could be understood that present day girls adapt easily to the socialisation processes and have the inclination to establish relationships with the society (Laible et al., 2004). Moreover, in the recent times, girls have begun venturing into all kinds of activities individually might have influenced them to have better social competencies than their counterparts.The results of the interaction effect of attachment styles and gender also strongly support the view that adolescents are differing on their attachment styles as well as gender with regard to their social competencies. 


\section{Findings}

The following major outcomes were drawn from the investigation

1. Theadolescents with secure and insecure attachment styles considerably differ on social competence.

2. The adolescent boys and girls are significantly varied on their socialcompetencies. In that, the adolescent girls are better on their social competencies.

3. There is a significant interaction effect of attachment stylesandgender on social competence.

\section{Implication}

The present study could evoke the following implications.

1. The attachment styles have influencing effect on the development of human behaviour in the social contexts of adolescents.

2. The secure attachment styles establish positiveand safe social abilities of adolescents.

3. Evolving training to enhance secure attachment style is imminent.

4. Gender specific programsneed to be designed for enhancing social competencies.

5. Adequatecounselling and guidance curriculum has to be evolved in Schools.

\section{Conclusion}

It can be concluded that attachment styles are exceptionally essential elements in the lifespan development of individuals. Enhancing as well as improving secure attachment styles during adolescent period is very imminent. Evolving of effective strategies for enhancing secure attachment stylesneedsto be launched straight awayto advance the behaviours of adolescent students. 


\section{References}

Ainsworth, M. D. (1985). Patterns of infant-mother attachments: antecedents and effects on development. Bulletin of the New York Academy of Medicine, 61(9), 771.

Ainsworth, M. D. S., Blehar,M.C., Waters, E., \& Wall, S. (1978). Patterns of attachment: A psychological study of the strange situation. Hillsdale, NJ: Lawrence Erlbaum.

Ainsworth, M. S. (1989). Attachments beyond infancy. American psychologist, 44(4), 709.

Allen, J. P., Moore, C., Kuperminc, G., \& Bell, K. (1998). Attachment and adolescent psychosocial functioning. Child Development, 69(5), 1406-1419.

Armsden, G. C., \& Greenberg, M. T. (1987). The inventory of parent and peer attachment: Individual differences and their relationship to psychological well-being in adolescence. Journal of youth and adolescence, 16(5), 427-454.

Bartholomew, K., \& Horowitz, L. M. (1991). Attachment styles among young adults: a test of a four-category model. Journal of Personality and Social Psychology, 61(2), 226-44. Retrieved from http://www.ncbi.nlm.nih.gov/pubmed/1920064

Bowlby, J. (1969). Attachment and Loss. New York: Basic Books.

Bowlby, J. (1982). Attachment and Loss: Vol. 1. Attachment (2nd ed.). New York: Basic Books.

Bowlby, J. (1988). A SECURE BASE Parent-Child Attachment and Healthy Human Development. New York: Basic Books.

Brown, B. B., \& Klute, C. (2003). Friendships, cliques, and crowds. In G. R. Adams \& M. D. Berzonsky (Eds.), The Blackwell handbook of adolescence (pp. 330-348). Malden, MA: Blackwell.

Cohn, D. A. (1990) Child-mother attachment of six-year-olds and social competence at school. Child Development, 61(1), 152-162.

Denham, S., Mason, T., Caverly, S., Schmidt, M., Hackney, R., Caswell, C., \& DeMulder, E.(2001). Preschoolers at play: Cosocializers of emotional and social competence. International Journal of Behavioral Development, 25(4), 290-301. 
Devassy, V. P., \& Raj, J. M. (2012). Adolescents' social competence: development and validation of Adolescent Social Competence Scale (ASCS). Asian Journal of Development Matters, 6(2), 293-307.

Elicker, J., Englund, M., \&Sroufe, L. A. (1992). Predicting peer competence and peer relationships in childhood from early parent-child relationships. In R. D. Parke \& G. W. Ladd (Eds.), Family-Peer Relationships: Modes of Linkage (pp. 77-106). New Jersey:Lawrence Erlbaum Associates.

Granot, D. \& Mayseless, O. (2001). Attachment security and adjustment to school in middle childhood. International Journal of Behavioral Development, 25(6), 530-541.

Gresham, F. M., \& Reschly, D. J. (1988). Issues in the conceptualization, classification, and assessment of social skills in the mildly handicapped. In T. Kratochwill (Ed.), Advances in school psychology (Vol. 6, pp. 203-247). Hillsdale, NJ: Erlbaum.

Kobak, R. R. \&Sceery, A. (1988). Attachment in late adolescence: Working models, affect regulation, and representations of self and others. Child Development, 59, 135-146.

Ladd, G. W. (1999). Peer relationships and social competence during early and middle childhood.Annual review of psychology, 50(1), 333-359.

Laible, D. J., Carlo, G., \& Roesch, S. C. (2004). Pathways to selfesteem in late adolescence: The role of parent and peer attachment, empathy, and social behaviours. Journal of adolescence, 27(6), 703-716.

Lefreniere, P. J., \&Sroufe, L. A. (1985). Profiles of peer competence in preschool:Interrelations between measures, influence of social ecology, and relation to attachment history. Developmental Psychology, 21(1), 56-69.

Mabey, J., \& Sorensen, B. (1995). Counselling for young people. McGraw-Hill Education (UK).

McFall, R. M. (1982). A review and reformulation of the concept of social skills. Behavioral Assessment, 4, 1-33.

Mikulincer, M., \& Shaver, P. R. (2005). Attachment security, compassion, and altruism. Current directions in psychological science, 14(1), 34-38. 
Osman, B. (2001). Nurturing social competence in a child with learning disabilities. Learning Disabilities, 4(2), 56-67.

Rosenstein, D. S., \& Horowitz, H. A. (1996). Adolescent attachment and psychopathology.Journal of consulting and clinical psychology, 64(2), 244.

Sanson, A., Hemphill, S. A., \& Smart, D. (2004). Connections between temperament and social development: A review. Social Development, 13(1), 142-170.

Shulman, S., Elicker, J., \&Sroufe, L. A. (1994). Stages of friendship growth in preadolescence as related to attachment history. Journal of Social and Personal Relationships, 11, 341-361.

Thompson, R. A. (2000). The legacy of early attachments. Child development, 71(1), 145-152.

Van Oudenhoven, J. P., Hofstra, J., \& Bakker, W. (2003). Ontwikkelingenevaluatie van de Hechtingstijlvragenlijst (HSL) [Development and evaluation of the Attachment Styles Questionnaire]. NederlandsTijdschriftvoor de Psychologie, 58, 95102. 